\title{
The Effects of Various Anions and Cations on the Lysis of Yeast Protoplasts by Osmotic Shock
}

\author{
By K. J. INDGE \\ Department of Biochemistry, University of Manchester Institute of \\ Science and Technology, Manchester
}

(Accepted for publication 26 October 1967)

SUMMARY

The lysis of yeast protoplasts as a function of the tonicity and composition of the suspension medium was examined. The resistance of the protoplasts to lysis by osmotic shock was lowered by certain chelating agents and at low $\mathrm{pH}$ values. The effects of chelating agents on the lysis of the protoplasts were inhibited by $\mathrm{K}^{+}, \mathrm{Na}^{+}, \mathrm{Mg}^{2+}$ and spermidine. Chelating agents increased lysis only when the protoplasts were undergoing osmotic stress, and the cations did not influence lysis unless chelating agents were also present. The presence on the protoplast membrane of a cation-binding site which is involved in maintaining the structure of the membrane is inferred.

\section{INTRODUCTION}

The lysis of bacterial protoplasts is influenced not only by the relative permeability of the protoplast membrane to various solutes, but also by the ability of certain compounds to interact with the membrane itself (McQuillen, 1960; Mager, I959; Harold, 1964; Marquis, 1965). Apart from the usefulness of such studies in providing a basis for a systematic approach to the problems of obtaining stable protoplast preparations, they may lead to a better understanding of the properties of the protoplast membrane. A variety of stabilizing media have been used by different workers to preserve yeast protoplasts during their preparation and subsequent storage (Gascon \& Villanueva, 1965), but in this case few attempts have been made to study the response of the protoplasts to the various solutes used. In the present work the effects of certain anions and cations on the lysis of yeast protoplasts by osmotic shock was examined.

\section{METHODS}

Preparation of yeast protoplasts. The yeast used was a strain of Saccharomyces carlsbergensis NCYC 74. The protoplasts were isolated by a method based on that of Eddy \& Williamson (1957, 1959). Dried snail-gut juice $(2.5 \mathrm{mg} . / \mathrm{ml}$. of Helicase. Industrie Biologique Française, 49 Quai Du Moulin De Cage, Gennevilliers, Seine, France) was used to dissolve the cell wall, the digestion medium being buffered with $0.0 \mathrm{I} \mathrm{M}$-imidazole $\mathrm{HCl}$ at $\mathrm{pH} \mathrm{6.4}$. Less lysis occurred during protoplast formation under these conditions than in the citrate + phosphate buffer used by Eddy \& Williamson. The protoplasts were washed at $0^{\circ}$ in $10 \%(\mathrm{w} / \mathrm{v})$ mannitol solution containing $0.0 \mathrm{I} \mathrm{M}$ imidazole $\mathrm{HCl}$ buffer ( $\mathrm{pH} \mathrm{6.4)}$ ), suspended in this solution at a concentration of about ${ }_{10} 0^{9}$ protoplasts $/ \mathrm{ml}$. and stored at $0^{\circ}$ for up to 3 days. 
Osmotic lysis measurements. A series of tubes containing $5 \mathrm{ml}$. samples of an appropriate buffer and from 2 to $10 \%(\mathrm{w} / \mathrm{v})$ mannitol in $0.5 \%(\mathrm{w} / \mathrm{v})$ steps were prepared and brought to $25^{\circ}$. Protoplasts $\left(0.05^{-0} \cdot \mathrm{IO} \mathrm{ml}\right.$. of stock suspension) were added to the tubes of the series, the contents of which were then intimately mixed by shaking. The interval between the addition of protoplasts and the mixing of the solutions was about I min. The extinction of each suspension was measured at $5 \mathrm{~min}$. intervals for about 20 min. with a Hilger Spekker with $1 \mathrm{~cm}$. cells and Ilford H. 508 (neutral) filters. Extinction changes were correlated with lysis of the protoplasts by counting the intact cells in a Neubauer counting chamber.

In experiments where the effects of selected anions on the stability of the protoplasts were investigated the solutions were prepared from the free acids and brought to the required $\mathrm{pH}$ value with tris; other cations were added as the chlorides. Generally the contribution of the substance tested to the net osmotic pressure of the medium was not significant, but when necessary iso-osmotic conditions between the control series (no additions) and the test series were maintained by reducing the mannitol concentration in the test series appropriately.

\section{RESULTS}

The relationship between extinction changes and lysis

When samples of a stock suspension of protoplasts in $10 \%(\mathrm{w} / \mathrm{v})$ mannitol solution were added to hypotonic solutions of mannitol the extinction values of the mixtures decreased rapidly during the next 5-10 min. and were then almost constant. It will be seen from Fig. I that the initial decrease of extinction was greater the lower the concentration of mannitol in the suspension medium.

Extinction changes observed in suspensions of protoplasts or subcellular particles may result from both swelling and lysis. To estimate the relative contributions of swelling and lysis to the extinction changes recorded in these experiments samples of the protoplasts were suspended in various hypotonic media and the numbers of unlysed protoplasts counted after I5-20 min. A linear relationship between the number of intact protoplasts and the extinction value of the lysate was observed for a range of experimental conditions (Fig. 2).

In further tests the effects of swelling on the extinction readings were estimated by restoring the concentration of mannitol in the medium to $10 \%(\mathrm{w} / \mathrm{v})$ after the lysis period. Generally this treatment produced only a small increase in the extinctions of the test mixtures, indicating that the observed changes resulted mainly from lysis of the protoplasts. Under conditions where most of the protoplasts resisted lysis, swelling contributed more significantly to the observed extinction changes; but the effects were not sufficiently large to be revealed above the scatter of experimental points of Fig. 2.

In view of these findings extinction measurements were taken to provide an approximate measure of protoplast lysis in subsequent work, and the possible differential effects of swelling under the various test conditions were ignored.

\section{Measurement of lysis resistance}

The above observations implied that in a protoplast population there existed a distribution of resistances to lysis by osmotic stress, since not all the protoplasts lysed in a given hypotonic solution. This suggested that the response of the protoplasts to 
osmotic stress might be better represented in the form of resistance curves than in the form of progress curves as in Fig. I. To do this the extinction observed in a given suspension 15-20 min. after the protoplasts were added to the various hypotonic media was plotted against the respective concentration of mannitol (see Fig. 3). Plots of the experimental data on arithmetical probability paper (Papart et al. 1947) showed that in general the resistance curves determined from osmotic lysis tests made in a number of different media approximately followed a normal distribution. Therefore many of the results were condensed by reporting only the tonicity of the medium (in $\%, w / v$, mannitol) at the median of the resistance curve (the median tonicity). On this basis the influence of a certain compound on the resistance of the protoplasts to lysis was expressed quantitatively (in $\%, w / v$, mannitol) as the difference between the median tonicities in the presence and absence, respectively, of that compound. For convenience this quantity is called the osmotic shift, $C_{m}$.

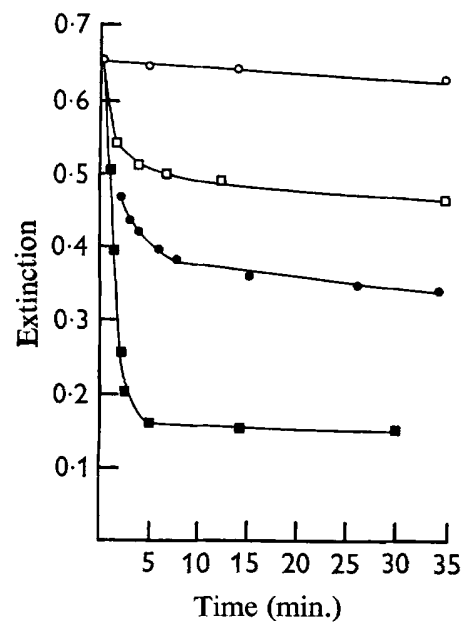

Fig. I

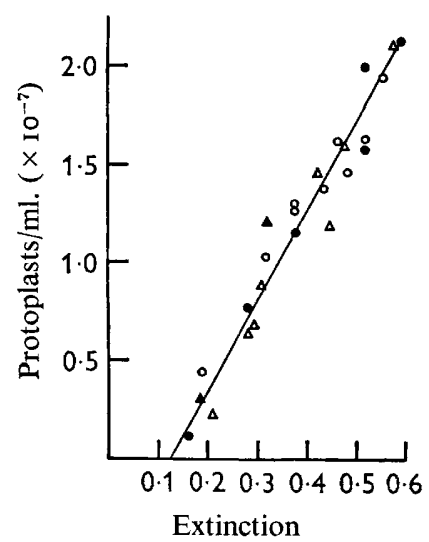

Fig. 2

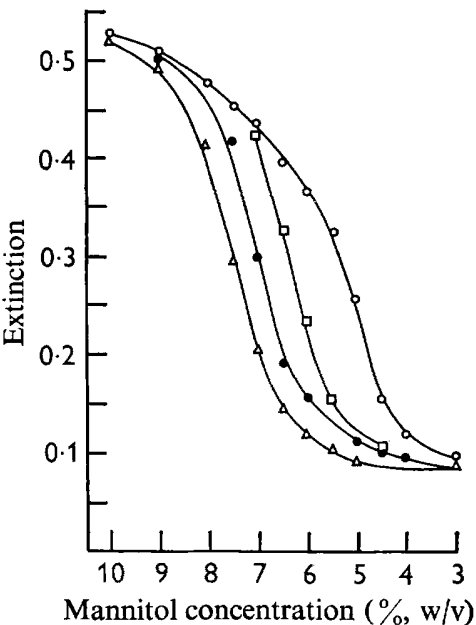

Fig. 3

Fig. I. Extinction changes with time during osmotic lysis of yeast protoplasts. The protoplasts were suspended at $25 \%$ in $10 \%(O), 6 \%(\square) 5 \%(0)$ and $4 \%(\square)$, w/v, mannitol solution buffered with $0.01 \mathrm{M}$-imidazole $\mathrm{HCl}(\mathrm{pH} \mathrm{6.4)}$.

Fig. 2. The relationship between the extinction and the number of unlysed protoplasts after the subjection of protoplast populations to osmotic stress. Protoplast populations containing about $2 \times 10^{7}$ protoplasts $/ \mathrm{ml}$. were partially lysed by osmotic shock in $0.0 \mathrm{I} \mathrm{M-imida-}$ zole $\mathrm{HCl}$ buffer (pH 6.4) (O); o.0 I M-imidazole $\mathrm{HCl}(\mathrm{pH} \mathrm{6.4})+0.0 \mathrm{I}$ M-citrate tris (O); O.OI M-imidazole $\mathrm{HCl}$ buffer $(\mathrm{pH} 6.4)+0.01 \mathrm{M}$-citrate tris $+0.0 \mathrm{I} \mathrm{M}-\mathrm{KCl}(\triangle)$; $0.01 \mathrm{M}$-succinate tris buffer $(\mathrm{pH} 5 \cdot 3)(\mathbf{\Delta})$.

Fig. 3. Osmotic lysis resistance curves showing the effects of citrate, $\mathrm{K}^{+}$and $\mathrm{pH}$ value on lysis. Protoplasts were lysed by osmotic shock in media containing graded amounts of mannitol. Lysis in 0.0 I M-imidazole $\mathrm{HCl}$ buffer $(\mathrm{pH} 6.4)(\mathrm{O})$; imidazole buffer + $0.0 \mathrm{I}$ M-citrate tris $(\triangle)$; imidazole buffer $+0.0 \mathrm{I} \mathrm{M}$-citrate tris $+0.0 \mathrm{I} \mathrm{M}-\mathrm{KCl}(\square)$; succinate tris buffer $(\mathrm{pH} 5 \cdot 3)(\mathrm{O})$.

\section{The influence of selected anions on lysis}

When osmotic lysis tests were carried out in the presence of citrate (0.0I M), progress curves similar to those shown in Fig. I were observed, except that complete lysis of the protoplast population occurred when the mannitol concentration was $6 \%(\mathrm{w} / \mathrm{v})$. 
This finding is illustrated by the resistance curves shown in Fig. 3. Table I shows that of the anions tested only those which are strong chelating agents, namely citrate, EDTA, ATP and to a lesser extent oxalate, pyrophosphate and isocitrate, decreased the resistance of the protoplasts to osmotic stress.

Protoplasts which were suspended in mannitol solution $(10 \%, w / v)$ together with citrate (O.OI M) or EDTA (O.OI M) did not lyse during $30 \mathrm{~min}$. When these protoplasts were then tested in the absence of these anions they exhibited resistance curves which were identical with those of untreated, control protoplasts. This finding indicated that certain anions were able to influence lysis only when the protoplasts were osmotically stressed. To examine this possibility further samples of a stock suspension of protoplasts were suspended in $6.5 \%(\mathrm{w} / \mathrm{v})$ mannitol solution and citrate (0.0I M) was then added at various times. The results of this experiment (Fig. 4) supported the idea that citrate increased lysis only when the protoplasts were undergoing osmotic stress. Similar results were obtained with ATP and EDTA.

\section{Table I. The effects of some anions on the osmotic lysis of yeast protoplasts}

Tests were made in 0.0 r $\mathrm{M}$-imidazole $\mathrm{HCl}$ buffer $\left(\mathrm{pH} \mathrm{6.4)}\right.$ ) and $25^{\circ}$. Anions (0.0I $\mathrm{M}$ ) were added as the tris salts. $C_{m}$ values were calculated as the difference between the median tonicities of the lysis resistance curves in the presence and absence, respectively, of anion. Deviations are the standard deviations and figures in parentheses the number of experiments.

\begin{tabular}{|c|c|c|c|}
\hline Anion (0.01 M) & $C_{m} \%(\mathrm{w} / \mathrm{v})$ mannitol & Anion (O.OI M) & $\begin{array}{c}C_{m} \%(\mathrm{w} / \mathrm{v}) \\
\text { mannitol }\end{array}$ \\
\hline Citrate & $2.2 \pm 0.2(20)$ & Succinate & $\circ(5)$ \\
\hline EDTA & $2.5 \pm 0.2(10)$ & Phosphate & $\circ(5)$ \\
\hline ATP & $2.5 \pm 0.25(6)$ & Sulphate & $0.1(3)$ \\
\hline Pyrophosphate & $\mathrm{I} \cdot 8 \pm 0.2(5)$ & Malonate & $o(3)$ \\
\hline Isocitrate & $I \cdot I \pm 0 \cdot I(6)$ & Glutamate & $o(3)$ \\
\hline Oxalate & $0.9 \pm 0.2(5)$ & Aconitate & $o(3)$ \\
\hline Acetate & $o(3)$ & Malate & $\circ(3)$ \\
\hline
\end{tabular}

\section{Lysis and anion concentration}

The relationship between the observed osmotic shift, $C_{m}$, and the concentration of chelating anion in the lysis medium is shown in Fig. 5. It can be seen that each anion tested produced a sharp increase in the lysis of the protoplasts over a fairly narrow range of concentration.

If it be assumed that: (I) these anions influence lysis by binding with receptor sites on the protoplast membranes, (2) the $C_{m}$ value is a measure of the extent of binding, (3) the amount of anion bound is a negligible fraction of the amount added, then these curves (Fig. 5) represent the dissociation functions of the complexes. On the basis of these assumptions the data were analysed by using a Scatchard plot (Sanui $\&$ Pace, 1962). The results showed that the data did not follow simple mass law relationships; they suggested that co-operative interactions might be involved.

\section{The influence of cations}

In the absence of chelating anions neither sodium chloride (O.OI $\mathrm{M}$ ) nor potassium chloride (0.01 $\mathrm{M}$ ) affected the osmotic lysis of the protoplasts at $\mathrm{pH} 6 \cdot 4$. However, these cations opposed the effects of those anions which decreased the resistance of the protoplasts to osmotic stress (Fig. 3). In a series of experiments the inhibition of the effects of ATP, EDTA and citrate on osmotic lysis by $\mathrm{K}^{+}$or $\mathrm{Na}^{+}$was investigated as a 
function of the $\mathrm{Na}^{+}$or $\mathrm{K}^{+}$concentration in the medium. Adopting analogous assumptions to those detailed above the data were analysed by using a Scatchard plot (Sanui $\&$ Pace, 1962). Plots of the osmotic shift, $C_{m}$, against $C_{m} /$ cation concentration for a range of concentrations of $\mathrm{Na}^{+}$or $\mathrm{K}^{+}$yielded straight lines (Fig. 6). The results were therefore consistent with a situation in which the formation of a reversible complex between $\mathrm{Na}^{+}$or $\mathrm{K}^{+}$and a binding site influenced the stability of the protoplasts. The validity of the interpretation is supported by the circumstance that the extrapolated

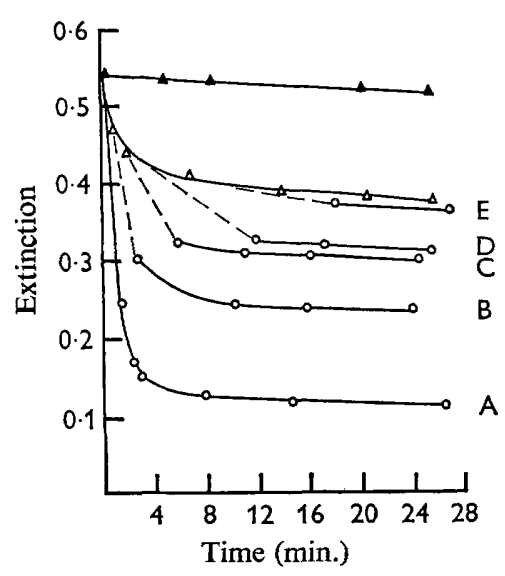

Fig. 4

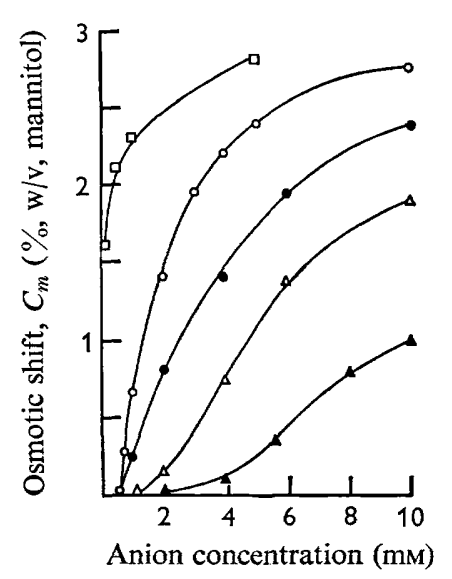

Fig. 5

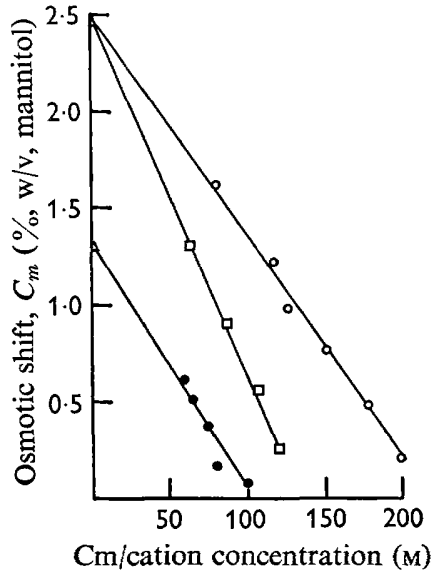

Fig. 6

Fig. 4. The effect of adding citrate ion during osmotic lysis of yeast protoplasts. Protoplasts were suspended in $0.01 \mathrm{M}$-imidazole $\mathrm{HCl}$ buffer $(\mathrm{pH} 6.4)$ containing $6.5 \%(\mathrm{w} / \mathrm{v})$ mannitol, and $0.01 \mathrm{M}$-citrate tris was added at time zero (curve A), after $0.5 \mathrm{~min}$. (curve B), after I min. (curve C), after $\mathrm{I} \cdot 5 \mathrm{~min}$. (curve D) and $5 \mathrm{~min}$. (curve E). Control tests in $10 \%(\mathrm{w} / \mathrm{v}$ ) mannitol solution (A) and $6.5 \%(\mathrm{w} / \mathrm{v})$ mannitol solution without citrate $(\triangle)$.

Fig. 5. Osmotic lysis of yeast protoplasts as a function of the concentration of chelating anion. Osmotic shifts $\left(C_{m}\right)$ plotted against the concentrations of EDTA ( $\left.\square\right)$, ATP (O), citrate $(\boldsymbol{O})$, pyrophosphate $(\triangle)$ and oxalate $(\boldsymbol{\Delta}) . C_{m}$ values were measured with respect to control tests in $0.01 \mathrm{M}$-imidazole $\mathrm{HCl}$ buffer $(\mathrm{pH} \mathrm{6.4})$ which contained no chelating anions.

Fig. 6. Scatchard plots showing the inhibition of lysis in the presence of citrate ions as a function of $\mathrm{Na}^{+}$or $\mathrm{K}^{+}$concentration. Experiments in $\mathrm{o} \cdot \mathrm{OI} \mathrm{M}$-imidazole $\mathrm{HCl}$ buffer $(\mathrm{pH} 6 \cdot 4)$. Osmotic shifts $\left(C_{m}\right)$ were calculated as the difference between the median tonicities of the lysis resistance curves without and with, respectively, added $\mathrm{Na}^{+}$or $\mathrm{K}^{+}$. Lysis in $0.0 \mathrm{I} \mathrm{M}^{-}$ citrate tris $+\mathrm{KCl}(\mathrm{O})$ and $\mathrm{NaCl}(\square)$. Lysis in $2.5 \mathrm{~mm}$-citrate tris $+\mathrm{KCl}(\mathbf{O})$. Points on the ordinate axis marked $\triangle$ were determined from control tests without added citrate and represent the osmotic shifts induced by citrate.

$C_{m}$ values for $\mathrm{Na}^{+}$and $\mathrm{K}^{+}$(Fig. 6), corresponding to saturation of the hypothetical binding site, were numerically equal to the osmotic shifts caused by the anions initially, i.e. it appeared that saturating concentrations of $\mathrm{K}^{+}$or $\mathrm{Na}^{+}$would exactly annul the effects of the chelating anions.

The apparent dissociation constants of the presumed $\mathrm{Na}^{+}$and $\mathrm{K}^{+}$complexes as deduced from the slopes of the Scatchard plots shown in Fig. 6 were $0.02 \mathrm{M}$ and O.OI M, respectively. Similar values were obtained from experiments in which EDTA, ATP or citrate was used to decrease the resistance of the protoplasts to osmotic stress. The apparent dissociation constant of the $\mathrm{K}^{+}$complex was unchanged as the con- 
centration of citrate (Fig. 6) or EDTA in the medium was varied. Thus $\mathrm{K}^{+}$behaved as a non-competitive inhibitor of the effects of these anions on the protoplasts.

Neither spermidine $\left(\mathrm{IO}^{-4} \mathrm{M}\right)$ nor magnesium chloride $\left(\mathrm{IO}^{-3} \mathrm{M}\right)$ affected the extinction changes during the osmotic lysis of protoplasts at $\mathrm{pH} 6 \cdot 4$ when chelating agents were absent. However, whereas lysis usually resulted in complete disruption of the protoplasts, the presence of these cations led to their gross structure being preserved. In the presence of either spermidine or $\mathrm{Mg}^{2+}$, citrate or EDTA had less effect on the resistance of the protoplasts to osmotic stress (Table 2). Concentrations of spermidine or $\mathrm{Mg}^{2+}$ greater than about $\mathrm{IO}^{-4}$ and $3 \times 10^{-3} \mathrm{M}$, respectively, caused precipitation of protoplast lysates accompanied by spurious extinction changes. For this reason a systematic study of their effects was not attempted. The addition of imidazole (O.0I M), tris (O.OI M) or triethanolamine (O.OI M) to tests made in media which were lightly buffered with $0.00 \mathrm{I} \mathrm{M}$-imidazole $\mathrm{HCl}(\mathrm{pH} \mathrm{6.4})$ either with or without EDTA $\left(\mathrm{IO}^{-4} \mathrm{M}\right)$ did not change the response of the protoplasts to osmotic stress.

Table 2. Inhibition of osmotic lysis of yeast protoplasts by spermidine and $\mathrm{Mg}^{2+}$

Experimental conditions as for Table I.

\begin{tabular}{|c|c|c|}
\hline \multirow[b]{2}{*}{ Addition } & \multicolumn{2}{|c|}{$\begin{array}{l}\text { Median tonicity of resistance } \\
\text { curve } \%(w / v) \text { mannitol }\end{array}$} \\
\hline & $\begin{array}{l}\text { EDTA } \\
(5 \mathrm{mM})\end{array}$ & $\begin{array}{l}\text { Citrate } \\
(4 \mathrm{mM})\end{array}$ \\
\hline None & $7 \cdot 8$ & $7 \cdot 0$ \\
\hline $\mathrm{MgCl}\left\{\begin{array}{l}\mathrm{I} \mathrm{O}^{-4} \mathrm{M} \\
\mathrm{I} \mathrm{O}^{-3} \mathrm{M} \\
2 \times 10^{-3} \mathrm{M} \\
4 \times 10^{-3} \mathrm{M}\end{array}\right.$ & $\begin{array}{l}7 \cdot 8 \\
7 \cdot 2 \\
6 \cdot 2 \\
-\end{array}$ & $\begin{array}{l}6 \cdot 8 \\
6 \cdot 0 \\
5 \cdot 6 \\
5 \cdot 4\end{array}$ \\
\hline No citrate or EDTA & $5 \cdot 3$ & $5 \cdot 3$ \\
\hline None & $7 \cdot 4$ & $6 \cdot 4$ \\
\hline Spermidine $\left\{\begin{array}{l}10^{-6} \mathrm{M} \\
10^{-5} \mathrm{M} \\
\mathrm{I} \mathrm{O}^{-4} \mathrm{M}\end{array}\right.$ & $\begin{array}{l}7 \cdot 2 \\
6 \cdot 7 \\
6 \cdot 3\end{array}$ & $\begin{array}{l}6 \cdot 3 \\
5 \cdot 9 \\
5 \cdot 8\end{array}$ \\
\hline No citrate or EDTA & $5 \cdot 0$ & 5.0 \\
\hline
\end{tabular}

The effect of $p H$ value

The resistance of the protoplasts to osmotic stress decreased as the acidity of the

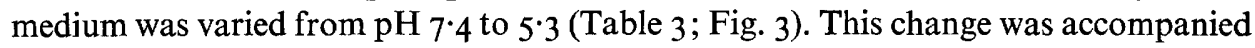
by a parallel decrease in the magnitude of the osmotic shift induced by citrate or by EDTA, a result which suggested that the effects of $\mathrm{H}^{+}$and chelating anions were related. The possibility that the succinate present in the buffer used for the tests at $\mathrm{pH} 5.3$ was responsible for the decreased stability of the protoplasts at this $\mathrm{pH}$ value was considered, but seems unlikely since unbuffered suspensions brought to $\mathrm{pH} 5$ with $\mathrm{HCl}$ lysed in a similar fashion.

A complication in the tests at $\mathrm{pH} 5 \cdot 3$ arose from the observation that the extent of lysis at this $\mathrm{pH}$ value appeared to vary with the rate of mixing of protoplasts with test medium. Large osmotic shifts resulted only when mixing was delayed for I-2 min. after the addition of the protoplasts to the medium (see Methods). The explanation of this phenomenon is not known. At higher $\mathrm{pH}$ values the rate of mixing of the suspensions was not important. 
$\mathrm{K}^{+}$and $\mathrm{Na}^{+}$were also effective in inhibiting the effects of low $\mathrm{pH}$ values on the response of the protoplasts to osmotic stress. The concentration dependence of the inhibition of lysis by these ions at $\mathrm{pH} 5 \cdot 3$ followed a simple adsorption isotherm with an apparent dissociation constant of roughly $\mathrm{IO}^{-2} \mathrm{M}$ for both $\mathrm{K}^{+}$and $\mathrm{Na}^{+}$; this figure is an approximate estimate and does not rule out the possibility of competition between $\mathrm{Na}^{+}$or $\mathrm{K}^{+}$and $\mathrm{H}^{+}$.

\section{Table 3. The influence of $p H$ value on the osmotic lysis of yeast protoplasts}

Tests at $\mathrm{pH} 7.5$ in $0.0 \mathrm{I} \mathrm{M}$-tris $\mathrm{HCl}$ buffer; at $\mathrm{pH} 6.4$ in $0.0 \mathrm{I} \mathrm{M}$-imidazole $\mathrm{HCl}$ buffer; at $\mathrm{pH} 5.3$ in $0.0 \mathrm{I} \mathrm{M}$-succinate tris buffer. Temperature $25^{\circ}$.

Median tonicity of resistance curve $\%(w / v)$ mannitol

$\begin{array}{lcccc}\text { pH } & \begin{array}{c}\text { No addi- } \\ \text { tions }\end{array} & \begin{array}{c}\text { Citrate } \\ (0 \cdot 01 \mathrm{M})\end{array} & \begin{array}{c}\text { EDTA } \\ (5 \mathrm{mM})\end{array} & \begin{array}{c}\text { Succinate } \\ (0.01 \mathrm{M})\end{array} \\ 7 \cdot 5 & 4 \cdot 7 & 7 \cdot 2 & 7 \cdot 4 & 4 \cdot 7 \\ 6.4 & 5 \cdot 1 & 7 \cdot 2 & 7 \cdot 4 & 5 \cdot 2 \\ 5.3 & 6.8 & 7 \cdot 3 & 7 \cdot 4 & 6 \cdot 8\end{array}$

\section{DISCUSSION}

The experimental findings show that only those anions which are strong chelating agents lowered the resistance of the yeast protoplasts to osmotic stress. Considering the different chemical natures of these anions, it seems reasonable to conclude that their effects arise from their common ability to form stable chelate complexes. There is considerable evidence in the literature to indicate that calcium and magnesium are involved in natural membrane structures (Sampson \& Karler, I963; Carvalho, Sanui \& Pace, 1963; Mikulecky \& Tobias, 1964; Asbell \& Eagon, 1966). Various papers, in which the association of membrane particles in the presence of magnesium ions has been reported, are particularly interesting from this viewpoint. (Blount, Rayner, Schmidt-Nielson \& Tosteton, 1963; Brown, 1965; Razin, Morowitz \& Terry, 1965). It is suggested therefore that the integrity of the yeast protoplast membrane depends on the presence of bound magnesium or calcium which can be replaced by $\mathrm{Na}^{+}$or $\mathrm{K}^{+}$. (Preliminary work has shown that appreciable amounts of magnesium are present in cell membrane preparations of the protoplasts.)

The lysis reaction may then be formulated as follows. In the absence of chelating agents osmotic stress leads to the swelling of the protoplasts to a point where the membrane is no longer impermeable to mannitol; lysis then ensues. When chelating agents are present magnesium is withdrawn from the membrane, leading either to a direct breakdown of its structure or to a change in its permeability properties; in either case mannitol penetrates into the protoplast and lysis results. Robinson (I966) suggested that a similar situation exists in brain microsome preparations. Since $\mathrm{K}^{+}$, $\mathrm{Na}^{+}$and spermidine influenced osmotic lysis only when chelating agents were added, it is suggested that these cations can substitute for magnesium in the membrane structure without changing its stability. Similarly, $\mathrm{H}^{+}$may compete with magnesium for binding sites on the membrane; but in this case leading to a structure with a decreased stability. It is relevant to note that competition between $\mathrm{Na}^{+}, \mathrm{H}^{+}, \mathrm{K}^{+}$and $\mathrm{Ca}^{2+}$ for binding sites of natural and model membrane systems has been reported (Rojas \& Tobias, 1965; Carvalho, Sanui \& Pace, 1963; Sanui \& Pace, 1965). 
On the basis of this model the results indicate that the magnesium of the membrane is not readily accessible to chelating agents in the medium since these anions were effective in decreasing the stability of the protoplasts only when these were undergoing osmotic stress. Two possibilities exist; either magnesium is exposed owing to the membrane becoming stretched, or the influx of water into the protoplasts enables the anions to penetrate the membrane structure. The former possibility requires that after the swelling phase the membranes of surviving protoplasts return to their original anion-insensitive state, presumably by loss of intracellular solutes and contraction. A similar synergistic action of chelating agents and hypotonicity on the stability of Escherichia coli protoplasts has been reported by Mager (I959).

The author is grateful to Professor A. A. Eddy for many helpful discussions and to $\mathrm{Mr}$ N. B. Roberts for technical assistance during this work.

\section{REFERENCES}

Asbell, M. A. \& EAGon, R. G. (I966). The role of multivalent cations in the organization and structure of bacterial cell walls. Biochem. biophys. Res. Commun. 22, 664.

Blount, R. W., Rayner, B., Schmidt-Nielson, B. \& Tosteton, D. C. (1963). Aggregation of fragments from sheep erythrocyte membrane when suspended in electrolyte solution. Fedn. Proc., Fedn. Am. Socs. exp. Biol. 22, 212.

Brown, J. W. (1965). Evidence for a magnesium dependent dissociation of bacterial cytoplasmic membrane particles. Biochim. biophys. Acta 94, 97.

Carvalho, A. P., Sanui, H. \& Pace, N. (I963). Calcium and magnesium binding properties of cell membrane materials. J. cell. comp. Physiol. 62, 31 I.

EdDy, A. A. \& Williamson, D. H. (I957). A method isolating protoplasts from yeast. Nature, Lond. I79, 1252.

EdDy, A. A. \& Williamson, D. H. (1959). Formation of aberrent cell walls and of spores by the growing yeast protoplast Nature, Lond. 183, I IOI.

GasCon, S. \& VillanUeVa, J. R. (I965). Magnesium sulphate as a stabiliser during liberation of yeast and mould protoplasts. Nature, Lond. 205, 822 .

HaRold, F. M. (1964). Stabilisation of Streptococcus faecalis protoplasts by spermine. J. Bact. 88, 1416.

MAGER, J. (1959). The stabilising effect of spermine and related polyamines on bacterial protoplasts. Biochim. biophys. Acta 36, 529.

MARQUIS, R. E. (1965). Osmotic stabilisation of bacterial protoplasts related to molecular size of stabilising solutes. Biochem. biophys. Res. Commun. 20, 580.

MCQuillen, K. (1960). In The Bacteria. Ed. by I. C. Gunsalus and R. Y. Stanier, vol. I, p. 249. New York and London: Academic Press.

MikUlecky, D. C. \& ToBias, J. M. (I964). Phospholipid-cholesterol membrane model. J. cell. comp. Physiol. 64, I5I.

Papart, A. K., Lorenz, P. B., Papart, E. R., GregG, J. R. \& Chase, A. M. (1947). The osmotic resistance (fragility) of human red cells. J. clin. Invest. 26, 636.

Razin, S., Morowitz, H. J. \& Terry, T. M. (I965). Membrane subunits of Mycoplasma laidlawii and their assembly to membrane-like structures. Proc. natn. Acad. Sci., Wash. 54, 219.

Robinson, J. D. (1966). Structural changes in microsomal suspensions. Arch. Biochem. Biophys. II3, 526.

Rojas, E. \& Tobias, J. M. (1965). Membrane model: Association of inorganic cations with phospholipid monolayers. Biochim. biophys. Acta 94, 394.

SAMPSON, S. R. \& KARLeR, R. (1963). Calcium-binding properties of skeletal muscle microsomes. J. cell. comp. Physiol. 62, 303.

SANUI, H. \& PACE, N. (I962). Sodium and potassium binding by human erythrocyte ghosts. J. cell. comp. Physiol. 59, $25 \mathrm{I}$.

Sanui, H. \& Pace, N. (1965). Mass law effects of adenosine triphosphate on $\mathrm{Na}, \mathrm{K}, \mathrm{Mg}$ and $\mathrm{Ca}$ binding by rat liver microsomes. J. cell. comp. Physiol. 65, 27. 